\title{
Arboreta and Gardens: Teaching Laboratories in the Undergraduate Curriculum-Introduction
}

Robert E. Lyons

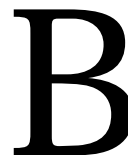

otanic gardens and arboreta have long been known for the importance of their collections, the beauty of their grounds, and the value of their educational programs. Their missions are as diverse as their origins, but when they are integrated into a college or university environment, their role as a teaching resource can be enormous. In fact, many institutions of higher education have successfully recognized and realized the value of an affiliated botanic garden or arboretum via a formal relationship with the undergraduate curriculum. The creativity of instructors, administrators and directors has diminished the perceived obstacle of distance for off-campus facilities, fostered the interaction between student and teacher, provided convenient opportunities for studying eclectic groups of plants in a single location, and allowed for the real-world use of student-driven construction projects. The student experience can be multifaceted and span the entire calendar, and in virtually every case, the relationship is mutually beneficial for students and institutions alike.

The development of this theme issue was greatly facilitated by $M$ ary $P$ at $M$ atheson, director of the R ed Butte $G$ arden- $U$ niversity of $U$ tah and other members of the American Association of Botanical Gardens and Arboreta (AABGA). The informal partnership which produced this set of papers is indicative of the great potential that exists for future collaborations between ASH S and AABGA. 